\title{
Moral and ethical issues in geriatric surgery
}

\author{
R Reiss 'Meir' Hospital, Kefar-Saba, Israel
}

\begin{abstract}
Editor's note
After preliminary definitions, the ethical questions arising particularly in the field of geriatric surgery are examined. The author finds no ethical justification for bias against the elderly patient as such in the allocation of scarce medical resources, nor for ignoring or overriding his wishes in respect of treatment; solutions must be based on the circumstances of the individual case. Criteria for withholding surgery in life-threatening situations are discussed but not endorsed, though pointers to decision-making are given, notably the value of the surgeon's sharing responsibility by interdisciplinary consultations with colleagues.
\end{abstract}

\section{Introduction}

Modern medical technology has given the physician awesome powers. His decisions not only affect life and death of the individual, but also have great influence over the rapidly increasing health expenditure in most countries.

In no area is the problem of such decisions as difficult as in geriatric surgery. At this age the dramatic interference with the course of events affects us daily as clinical surgeons.

There is no doubt that the central issue in every decision to operate or not, is a medical one: what are the chances of success in a given case ? However, in real life, other issues figure prominently, consciously or sub-consciously, the most important being:

a) Quality of life, both before and after surgery.

b) Capability of the patient to give informed consent.

c) Attitude of the surgeon and his willingness to take risks.

d) Economic considerations, such as expenses and availability of special services (intensive care unit).

While each one of us often faces such problems and solves them according to his beliefs, very little has been written on this subject, and no guiding criteria have been elaborated.

At this point we should attempt to discuss some basic ideas concerning surgical decisions in the geriatric group. I shall try to formulate some general guide lines and focus on abdominal surgery, the area in which my own experience lies. I hope that at least some of these ideas will be applicable to major procedures upon the elderly patient in other specialities.

\section{Historical review}

The ninetieth Psalm states: 'The days of our years are three scores and ten and if by reason of strength they be four score'-figures that have hardly changed to this day. The Greeks were the first to postulate a cause of ageing. Hippocrates (460-377 BC) called ageing an irreversible and natural event that was caused by a decrease in body 'heat'. Galen (130$201 \mathrm{AD}$ ) further elaborated on this theory and stated that ageing was primarily caused by a change in the body's humors which produced increased dryness and coldness. Maimonides (II35-1204) the Jewish philosopher stated that life was predetermined and unalterable but that our lifespan could be prolonged by taking suitable precautions. For almost a millennium, the ideas of the Greeks and Romans prevailed. No serious research on the process of ageing was carried out beyond alchemical search for the elixir of life.

In the last two decades much has been learned about old age in terms of statistical data and biology. Alexis Carrel (1873-1944) at the beginning of the century erroneously maintained that embryocells could be kept alive indefinitely in tissue cultures. Modern studies by Hayflick and others show that human diploid embryo fibroblasts have a finite lifespan in tissue culture of about 50 passages. Subsequent studies showed that animal cells had tissue-culture lifespan that were precise and almost proportional to their in-vitro lifespans.

The four most acceptable theories of ageing available are:

a) The genetic theory - a failure in DNA replication.

b) The autoimmunity theory - loss of immunological defence mechanism with age.

c) Accumulations of free radicals that cause deleterious changes of biologic systems.

d) A vertically transmitted ubiquitous slow virus, that may play a role in the ageing process.

\section{Statistical data}

Basic statistical data concerning old age have been presented by Comfort. These indicate, in essence, 
that if all known diseases could be cured, many more people would live to be seventy or eighty, but very few would still be alive at the age of ninety. His theories have so far been confirmed in that, while the percentage of people alive after seventy is much higher in western countries compared with the Third World, the same very small percentage live to be ninety in both areas.

Another statistical fact not generally appreciated is that the patient of seventy and above has a not inconsiderable life expectancy. Additional statistical data are relevant to the surgery of the old. The percentage of geriatric patients in the population of developed countries has increased from about 2 per cent at the beginning of the century to between 4-6 per cent now, and is certain to reach ro per cent in certain countries by the end of the century. Furthermore, because of population trends in some cities, the percentage of old people in the population might get close to I 5 per cent or more.

These numbers do not reflect the tremendous impact of the elderly on the medical system, because of the high incidence of degenerative metabolic and neoplastic disorders in this age group. Their incidence among patients hospitalised in a general hospital in our country is 15.2 per cent, specifically in departments of general surgery ( 20 per cent) and urology (34 per cent). Obviously, they are very heavily represented in certain types of surgical procedures, such as acute abdomenal surgery, amputations of gangrenous legs, prostatectomies and hip nailing.

Because of the frequent need for lengthy and costly rehabilitation it is not surprising that in countries with comprehensive health insurance systems, an estimated 24 per cent of all health expenditures is related to the geriatric segment of the population. Obviously, as this percentage of the total expenditure increases, so might the pressure to limit by legislation the astronomical cost of optimal medical care for the old.

One of the first issues we have to confront is: What is the proper age to choose as a definition of a geriatric patient? While the biological data are often more important than the chronological age, for statistical purposes a cut-off point has to be defined. No doubt this depends on the society we live in: forty-five may be old age in Nepal, seventy may be old age in Jerusalem and New York today, possibly eighty will be considered as the proper age in the next two decades. It is very important to make the distinction between functional age and formal age. It is the onset of biological deterioration sufficient to interefere with the performance of adult work tasks, which signals the onset of old age in those societies which accept functional age as a status determinant. Formal age, in contrast, is pegged to some external event which is artibrarily invested with symbolic significance.

In most commercial and industrial enterprises a worker is defined as 'old' at the age of sixty-five. Obviously, the correlation between functional age and formal age is very poor, as we physicians know from our practice. In our work we have used tie age of seventy as a cut off point for data reporting and investigation.

\section{Attitude of the surgeon}

'Because it is there' answered George Lei Mallory when asked about his desire to climb Mount Everest. This type of sentiment reflects the attitude of some surgeons. Many operations acte performed simply because of their feasibility. As more and more procedures become feasible arot safe in medicine, the problems of when to perfotm them become more complicated. Accusations in the media concerning unnecessary surgery are pe? sistent. This is true in modern medicine in general particularly so in surgery - the most expensive and risky segment of medicine.

The aim of surgery in the elderly is to improve the chances of the patient to achieve his life expectancy, or make his life more comfortable without und Đee risk. Some of the considerations governing such decisions are primarily medical and concerm calculable matters such as mortality rate, success in relief of severe symptoms or the possibilin of alternative therapy. Other matters are muen more complicated and cannot be strictly confined to conventional medical thinking. Matters such $\mathrm{AS}$ quality of life, dignity of death, expense to societ selection of patients when services are in shost supply - such matters are often raised and are very difficult to solve.

In principle, the decision to operate is no differeit at the age of eighty from that at the age of fift. In real life, however, such a decision is much move difficult and many more factors have to be con sidered. Probably nobody could argue that cas cinoma of the rectum or a gangrenous leg should nơt be treated surgically in a reasonably well preserved patient of eighty or even eighty-five. On the other hand, when the surgeons approach an old patiegt with various medical and social problems, the decision becomes more difficult and clearly involves ethical and moral issues.

In the setting of the modern medical centre, mote often than not the surgeon is strongly biased in favour of performing surgery. A few of the factoss affecting this are:

a) Enormous technical advances of surgery and resuscitation coupled with the somewhat naive belief in the powers of medicine.

b) Plentiful and sometimes unlimited funds made available by health insurance systems.

c) The moral and religious feelings of the patienter family and physician emanating from the Biblical injunction 'Thou shalt not kill' as well as the Hippocratic oath, are often interpreted as an 
absolute and uncompromising formula for the preservation of life under any circumstances.

To these important reasons one might add some less important but nevertheless operative in a hospital setting such as:

a) Fear of malpractice by omission.

b) The desire of young surgeon to operate.

c) The necessity to fill operating lists.

d) The pride in successfully performing a difficult procedure.

While the surgeon is often biased in favour of surgery, under some circumstances he might be prejudiced in the opposite direction and resent the idea of operating on a very old patient. Cohen in a recent psychiatric study devoted to the geriatric patient, discusses the reasons that may prevent the physician from providing the most effective treatment in geriatric cases. Among the most important factors he lists the following:

a) The aged stimulate the practitioner's fears about his own age.

b) Elderly patients arouse the practitioner's conflicts about his relationships with parental figures.

c) The practitioner thinks he has nothing to offer old people because he believes that they cannot change their behaviour or that their problems are all due to untreatable organic brain disease. d) The practitioner believes that his skills will be wasted with the aged because they are near death and not really deserving of attention.

e) The patient might die while in treatment, which could challenge the practitioner's sense of importance.

While the decision to perform or not to perform a surgical procedure on an old and deteriorated patient may be ethically and morally debatable, there is no such controversy as far as post-operative care is concerned. Once surgery is performed, there is a binding moral contract between the patient and the surgeon to use every available technique that can benefit the patient. There is absolutely no moral or ethical justification to withhold from the old patient techniques such as intravenous alimentation, intensive care, haemodialysis - if medically indicated - for economic or other reasons. If the number of beds in an Intensive Care Unit is limited, there is no moral justification to discriminate against the elderly, as occasionally happens. The appropriate allocation of beds should be made on the basis of medical need and chances of successful treatment in the unit.

\section{Attitude and legal rights of the patient and his family}

An important role in the decision-making process can be played by the patient if he is lucid and capable of informed consent. Fortunately, such is the case with most elderly patients and the operative decision is reached after a thorough discussion between the surgeon and the patient, just as it is in the younger age group. Is the right of the patient to refuse surgery after proper explanation to be limited? If the surgeon feels that a given operation is absolutely necessary may he try to influence the patient to have it ? Some authors such as Ramsey, seem to imply as much by claiming that the patient's refusal to undergo surgery should be restricted and reasonable. Ramsey explains that even the competent patient should be protected against a morally wrong decision - he should not be allowed to reject life and choose death. In clinical practice we feel that there is no way to restrict the free choice of the patient because of his age. The fact that the medical team recommends surgery and the family support the idea does not diminish the moral right of the patient to refuse treatment. If a patient refuses to have his gangrenous leg removed, a colostomy constructed or indeed if he refuses any surgery, one should abide by his wishes and use the best alternative means of therapy available.

A much more complicated problem is that of the incompetent or not fully competent elderly patient. The decision to be reached in such cases is very difficult and no unequivocal answers exist. One theory maintains that under such circumstances the decision should be made by the surgeon and he should be guided by what in his opinion most competent patients would elect to do under similar conditions. Others, such as Zachary or Veatch have used much more restrictive criteria recommending surgery only if meaningful survival could result from the contemplated procedure. The term passive euthanasia has been used under such circumstances - but in our view it hardly applies to not performing surgery.

Is the law capable of giving us solid guide-lines concerning so-called passive euthanasia? It does not seem so. Louisell, in a lengthy review of euthanasia, refuses to lend support to the legalisation. He states: 'Our era is one that seeks, and often for good reason, a constant expansion of juridical order in human affairs. But not every human relationship stands to profit from complete juridicalisation. The refusal so far of legislatures to intrude into the mercy-death area has been prudent'. The dilemma may be described as follows: should surgery be performed in very old, bed-ridden patients, with advanced degenerative disorders of the central nervous system, or very advanced carcinomatosis? If an acute surgical complication, such as bleeding or a peritonitis occurs in such a patient, is one justified under some circumstances not to recommend surgery? Are there any circumstances justifying withholding a surgical procedure in life threatening situations and if so, what are the circumstances? Two types of criteria have been recommended and considered: 
a) Ordinary versus extra-ordinary care. Many moralists and theologians maintain that the dying or terminal patients should receive only what is described as ordinary or standard treatment. There is no obligation, moral or ethical, to use unusual and extraordinary means to prolong artificially the life of such a patient. In practice this is not a very useful criterion for a surgeon as it raises more questions than it answers. Determining whether a patient is terminal or not is practically difficult and often impossible in surgical emergencies. It is even more difficult if not impossible to define ordinary as against extra-ordinary care under such circumstances.

Is a surgical procedure of any type extraordinary or standard? Are some procedures, such as opening of an abscess or amputation ordinary and others, such as radical surgery for cancer extraordinary? Obviously, this distinction is not of great practical use.

b) A second criterion often proposed but equally difficult to use is the criterion of anticipated quality of life. It is based on the belief that below a certain standard of quality and function, life is not worth living.

According to this argument, if one cannot expect to restore by surgery a minimal standard of quality of life, no surgery should be proposed. Rhoads argues very strongly for this approach: 'The mortality of life is roo per cent. Death is inevitable. There is no special virtue in staving it off indefinitely. But living must be made as comfortable as possible. The general message must be that medicine now should be more orientated to the fact that it is more concerned with the comfort of individuals than with the prevention of death, which has been its prime concern for centuries'. While the standard of quality of life is something that cannot be ignored, and will probably be invoked in the future with increasing frequency at present one should use it with very great caution.

There are great dangers for a surgeon to use the argument of quality of life, as a justification for not recommending surgery in cases of acute abdomen or, massive bleeding. In our experience such cases are exceedingly rare. Indeed, if the surgeon feels that the likelihood of a successful outcome is high he will insist on operating, especially under emergency circumstances - except under most unusual conditions. If such unusual circumstances do occur the issue and the reasons for not operating should be thoroughly discussed with the patient and the family if at all feasible.

A case offering a glimpse of the difficult issues involved concerning the incompetent patient was that of Joseph Saikewicz. While the case dealt with chemotherapy it is also relevant in deciding whether to operate on an incompetent patient. Late in 1977 the Massachusetts Supreme Court issued a written opinion explaining why it had intervened to ordis physicians to stop treating Joseph Saikewioz. Saikewicz was a 67-year-old man suffering frow acute myeloblastic monocytic leukaemia. What made his case unique was that he was profound retarded (IQ of Io). He had been institutionalised since 1923 and was unable to understand the burdeonsome treatment proposed for him or the choices the would have to be made about chemotherapy, which would offer at most a temporary remission. ORe should briefly review the arguments of both sides the Saikewicz case, for they are very relevant to the dilemma of operating on old and legally incom petent patients.

IN FAVOUR OF TREATMENT

a) The life of the patient may be extended.

b) The majority of people in a like situation would probably accept treatment.

c) There is no way to determine whether the expected quality of life should be so low that trearment should be refused.

\section{AGAINST TREATMENT}

a) Poor chances for long survival.

b) Suffering and anguish related to intensike therapy such as pain, transfusion, tubes dressing, as opposed to relatively painless death in sonf circumstances.

c) Competent adults in the same situation woulf have the option to refuse therapy and some, doubt, would do so.

The decision of the court re-emphasises the absolute right of the lucid patient to refuse life prolonging treatment. However, it does not suf ciently clarify the respective role of the surgeon and the family in border line cases. By placing the fing authority in difficult cases with the courts, i proposed a solution that is applicable to very fe elective cases and practically no emergenciess. Another of the court rulings that is worth mention ing is a statement concerning the mentally inconz petent patient 'To the extent that this formulation equates the value of life with any measure of thes quality of life, we reject it'. This statement of the court seemingly rejects completely the consideratio of quality of life as a basis of not performing surgery in life threatening conditions.

In conclusion, the two sets of arguments seet well balanced and the decisions in concrete case will have to depend on the best interest of the patient. It seems to us that the experienced phy sician is in a much better position to make suct judgment than either the family or a court of lawe In border-line cases, we have found the following three measures to be of great value:

a) Consideration of the functional and neuroo logical status of the patient, prior to the onset of the acute problem. 
b) The great value of multidisciplinary consultations in a difficult decision, sharing the responsibility with a gerontologist, a psychiatrist and a gastro-enterologist or other relevant specialist.

c) The attitude of the family while not legally binding is of paramount importance in directing our therapeutic approach to the incompetent patient. We tend to abide by the family decision in such matters - in all but the most exceptional cases.

While its opinion is clearly not legally binding, while it cannot substitute its will for the will of the patient - in incompetent, senile or comatose patients - the will of the family must be considered. It is worth while, therefore, to discuss briefly possible attitudes of the family toward the geriatric patient.

Firstly the present day public, educated by the communication media, is well aware of the impact of surgical procedures and the use of life-prolonging techniques. The public is aware of the questions that have been raised concerning the capabilities of medicine to alter the quality of human life and may be highly critical of some types of activities that seem natural to us as doctors. One also has to realise that while most families are devoted to the elderly patient under their care, others may be consciously or sub-consciously strongly biased against the patient for emotional and economic reasons. We would like to conclude that our primary ethical and moral obligation is to the patient and not to the patient's family, and we should not abdicate too easily the right to make the proper decision medically whilst making every attempt to gain the family's consent and willing cooperation. Such a course will help in the patient's recovery and rehabilitation and it will also diminish the risk of litigation and malpractice suits.

\section{Economic considerations}

The last issue that has to be considered is the economic one. We live in an era of exploding health expenditure and desparate attempts by society to contain costs.

A hospital cost containment bill is at present being considered by the US Congress. One target of administrators, and even some surgeons eager to contain costs, may be the geriatric patient who is practically always not productive, often poor and occasionally severely handicapped.

A recent editorial in the New English Journal of Medicine states in this respect: 'We have been told that various economic dislocations make it necessary for this country to reconsider its priorities, to husband its dwindling resources and to cut back expenditure on items that are not of vital national import'. Such considerations are not purely theoretical - and may very well be used to interfere with optimal care of geriatric patients. It is our view that decisions concerning the allocation of a proportion of the nation's resources to medicine in general and to its various subspecialities are political decisions and possible cuts in some areas are necessary for the public good. On the other hand, the individual surgeon caring for the individual patients cannot afford to have such considerations in mind. Every means of medical therapy should be used, provided it is available and believed by the surgeon to be beneficial to his patient. In our view it would be un-ethical, immoral and discriminating to refuse, certain types of care in geriatric patients on the basis of financial considerations - while the same therapy is routinely carried out in younger patients.

\section{Factors influencing surgical mortality in geriatric patients}

Surgical mortality in the strict sense does not belong to the moral and ethical issues, yet, if old age combines with terminal illness or severe debility, the contra-indications may well be greatly increased over other patients, and corresponding greater regard would have to be given to the risk factor. In other words, whilst a forty :sixty chance of success may well justify an operation in younger patients, such a risk might be unacceptable in geriatric cases where the expectancy of life is already compromised by factors other than mere old age. The tremendous advances in anaesthesia, intensive care and surgery have dramatically reduced the mortality of major abdominal procedures in the elderly. To comment on this tremendous change in respect to surgical mortality we would briefly like to report on our study concerning 325 laparotomies in patients above seventy. This entire group was operated upon after 1969 and advanced anaesthesia techniques (Neurolept analgesia) were combined with careful operative and post-operative monitoring. The surgical policy was based on the premise that early surgery is the best solution to abdominal emergencies involving sepsis or blood loss in the elderly patient.

The number of laparotomies in elderly patients has increased by more than I0O per cent over the last decade. This reflects a new and more optimistic attitude to surgery in such patients. The mortality in the entire series was remarkably low -6.4 per cent. The analysis of different groups shows a low mortality in elective procedure for benign disease, and for curative cancer procedure. Moderate increase is noted for emergency procedures in benign situations. The only group that carries a high mortality of 30 per cent are palliative procedures for patients with advanced intra-abdominal malignancy.

These figures are a strong argument for trying to establish the diagnosis by non-invasive techniques 
and trying to avoid surgery in geriatric patients with advanced malignancy. An important factor influencing mortality is the involvement of life support systems. Marked increase in mortality is present when more than one system is involved. Differences in age within the group and duration of surgery did not play an important role as far as mortality was concerned. One year follow-up in this group demonstrates the excellent result as far as quality of life is concerned. Once patients with incurable malignancy were deducted, more than $3 / 4$ of the group were alive and in good functional status one year after surgery.

\section{Conclusions}

In every scientific study we try to draw clear-cut conclusions. This is obviously not possible in this instance. We would like, however, to attempt to formulate some rules that may be of help in reaching decisions in borderline cases. All difficult decisions in geriatric patients can be established only on an individual basis and based on thorough knowledge of the individual patient, his mode of life and his family. Solutions should be found, based on the circumstances of each case rather than by means of a dogmatic formula approach. At the edge of life the decisions have to be based on science but tempered by compassion and humanity.

The most important attribute for the surgeon is to have the correct philosophy in relation to the geriatric patient. Such a philosophy is guided by clinical experience and judgment and founded on sound biological principles. The competent and lucid patient has to be treated as a full and well informed partner in the operating decision and informed of the risks and alternative modes of therapy. On the rare occasions when the patient does not accept our recommendation and refuses surgery we have to abide by his choice unconditionally. On the freedom of choice of the competent patient Judge Schroeder of the Kanas Supreme Court in 1960 declared: 'A doctor might well believe that an operation is desirable or necessary but the law does not permit him to substitute his own judgment for that of the patient by any means'. Legally, the family does not seem to have a definite role in the decisions to be made; in practical terms however, the function of the family is of great importance. The family's consent and goodwill, will help in the patient's recovery and rehabilitation and diminish the risk of malpractice suits.

Most of the etbical decisions concerning geriatrics can only be taken by experts, because they alone have the expert knowledge. There are, of course, a few ethical decisions which can be painted in black and white, but most ethical decisions involve a choice between different tones of grey. Here expert knowledge is tremendously important. Multi- disciplinary consultations with experts in field of psychiatry, geriatrics and rehabilitation are of great value to the surgeon and permit sharing of responsibility in difficult cases. The distinction between ordinary means of therapy, which a obligatory, and extra-ordinary ones, which are optional, has very little meaning for the surgeom and cannot usefully be considered while makin difficult decisions. The notion of expected qualie of life is of course valid and significant but because of its subjective and unpredictable nature, it can only be considered within a spectrum of other considerations.

Economic reasons obviously play a determining part in the availability and delivery of surgicas care in various parts of the world and even various parts of the same country. While this is true in the case of individual surgeons treating an individual patient it would be unethical and immorat not to recommend, for financial reasons, speciff therapeutic methods that can be of benefit to the patient. It is the duty of the surgeon to use advanced methods such as haemodialysis, intensive care unit intravenous alimentation for the old patient, just as he would for the young, provided he feels thef are medically indicated and available in his hospital. The great complexity of caring for the old requiring major surgery, raises the possibilit that some might attempt the creation of a net sub-speciality: geriatric surgery. In our view suct development would be useless and might even be harmful to the old surgical patient by separating him from the younger group and possibly relegating him to second grade care.

On the other hand, because of the fact that the general surgeon as well as many surgical specialis have to deal with the old with ever increasing frequency - much more emphasis should be put on geronto-surgery in medical education and surgical residency training. More intensive exposure to geriatric problems will permit the surgeon to make the individual and social decisions necessary in the care of the aged with wisdom and authority.

\section{Bibliography}

Bloch, H (1978). Medical Ethics and Moral responsibilit New York State fournal of Medicine, 665, March. O

Binstock and Sharrs (1976). Handbook of ageing and the social sciences, New York. Van Nostrand Reinholf Company.

Brown, N K, Bulger, R J, Laws, H E et al. (1970) The preservation of life. fournal of Americas Medical Association, 21 1 : 76.

Cohen, G D (1977). Approach to the geriatric patient कै Medical clinics of North America, 61, 855.

Comfort, A (1956). The biology of senescence, Hot Rinehart Wilson.

Cowdry, E V and Steinberg, F U (Eds.) (1971). The car of the geriatric patient, Mosby. 
Editorial (1973). New horizons in medical ethics. British Medical fournal, 648-653, I6 June.

Hay, F (1974). The longevity of culture human cells. Geriatric Society, 22, I.

Montefiore, H W (I969). Ethical problems of geriatrics. Geront. Clinica, I1, 65-74.

Ramsey, P (1978). Ethics at the edges of life, Yale University Press.

Rossman, I et al. (Eds.) (I97I). Clinical geriatrics, Philadelphia, Lippincott.
Powers, $\mathrm{R}$ (1968). Surgery in the aged patient, Philadelphia, Saunders.

Veatch, $\mathbf{R}$ (1977). Death, dying and the biological revolution, Yale University Press.

Vowles (1979). Surgical problems in the aged, London, Wright.

Wallace, D J (I97I). The biology of aging. Fournal of American Geriatric Society, 25, 104.

Watson, C G (1977). Can and should the ethics of a cottage industry survive, Arch Surg II2, I III. 